\title{
A supervisão como processo educativo: Construindo o paradigma de reduçáo de danos emancipatória com uma equipe de CAPS-AD
}

\author{
Luciana Cordeiro, Aline Godoy, Cassia Baldini Soares \\ Departamento de Enfermagem em Saúde Coletiva, Escola de Enfermagem, Universidade de São Paulo - USP,
}

São Paulo, SP, Brasil

\begin{abstract}
Resumo: Introdução: O consumo contemporâneo de drogas ocupa lugar de destaque nas políticas públicas e na mídia. Diferentes formas de enfrentar a problemática vêm se apresentando, sendo uma delas a Redução de Danos Emancipatória, um movimento social antiproibicionista baseado no desenvolvimento de crítica sobre a realidade a fim de transformá-la. Objetivo: Discutir processo de supervisão em um Centro de Atenção Psicossocial para Álcool e outras Drogas, CAPS-AD de uma cidade do estado de São Paulo com a finalidade de transformar as práticas da equipe de saúde, refletindo sobre o processo de produção em saúde e os processos de trabalho. Método: Compreendeu-se a supervisão como processo educativo emancipatório, utilizando-se o referencial teórico da Saúde Coletiva. Seis encontros foram realizados com a equipe do serviço. Resultados: A supervisão configurou-se como processo educativo crítico, visando à emancipação dos usuários e trabalhadores do serviço. Discussão: O processo de supervisão pautado no referencial crítico possibilitou o desenvolvimento de práticas da equipe de saúde fundamentadas na Redução de Danos Emancipatória.
\end{abstract}

Palavras-chave: Educação em Saúde, Saúde Pública, Saúde Mental, Redução do Dano, Transtornos Relacionados ao Uso de Substâncias.

\section{Supervision as an educative process: Building Emancipatory Harm Reduction paradigm with a mental health team}

\begin{abstract}
Introduction: The contemporary drug consumption has been highlighted in the public policies and by the media. Different forms of coping with this issue are being constructed. Emancipatory Harm Reduction, an antiprohibitionist social movement based on the development of critical conscience about the reality in order to transform it, is one of them. Objective: To discuss the supervision process of a public community mental health institution focused on treatment of problematic consumption of drugs in a municipality of the state of San Paulo, aiming to transform the mental health team practices, reflecting about the health production process and their work process. Method: A Collective Health theoretical framework was used to base the supervision in an emancipatory educative process. The process occurred in six meetings with the health care team. Results: The supervision was configured as a critical educative process, and its objective was the emancipation of the institution's workers and users. Discussion: The supervision process based on critical theoretical framework enhanced the development of the mental health team practices, based on Emancipatory Harm Reduction.
\end{abstract}

Keywords: Health Education, Public Health, Mental Health, Harm Reduction, Substance-related Disorders.

Autor para correspondência: Cassia Baldini Soares, Departamento de Enfermagem em Saúde Coletiva, Universidade de São Paulo, Av. Dr. Enéas de Carvalho Aguiar, 419, Sala 233, 2o. andar, Cerqueira Cesar CEP 05403-000, São Paulo, SP, Brasil, e-mail: cassiaso@usp.br Recebido em 03/09/2013; Revisão em 21/02/2014; Aceito em 04/05/2014 


\section{Introdução}

Marcado por fortes contradiçóes, o consumo contemporâneo de drogas vem ocupando lugar de destaque nas políticas públicas e na mídia. Por um lado, constata-se na mídia propagandas que incentivam o consumo de álcool (VENDRAME; PINSKY, 2010) e de medicamentos, com maior expressividade a partir da década de 1990 (BUCHER, 1992). Por outro lado, anuncia-se o combate a uma "epidemia do crack", alarmando famílias, cobrando o poder público e desestabilizando as poucas instituiçôes de saúde que lidam de maneira responsável com o problema.

Nappo (2012), ao discutir a suposta "epidemia do crack", denuncia a ausência de fundamentos nas publicaçóes alarmantes da mídia e nas produçôes acadêmicas, que não apresentam dados científicos confiáveis para sustentar o alarde. A autora explica que não há evidência científica que sustente a ocorrência de uma epidemia relacionada ao consumo de crack.

Nappo (2012) atenta ainda para os riscos desse alarmismo: problemas de ordem social e econômica dos grupos consumidores de crack, que pertencem a fraçôes da classe trabalhadora "sobrantes" e marginalizadas, podem ser atribuídos exclusivamente à substância; aumento da exposiçáo e preconceito em relação aos consumidores de crack; possibilidade de gerar açóes equivocadas para as quais se aplicariam os recursos disponíveis. O fato é que é possível observar a concretizaçáo dessa previsão, por exemplo, nas ações policiais de janeiro de 2012 e janeiro de 2013, no bairro da Luz, em São Paulo, SP, em que muitos recursos foram investidos em açóes pontuais, que provocaram reação da mídia, da sociedade civil e dos movimentos sociais (BONIS, 2012)

Na política do Ministério da Saúde para atenção a usuários de drogas, o estado assumiu seu histórico atraso em relação ao cuidado dos consumidores de drogas (BRASIL, 2004). A atenção do poder público brasileiro voltou-se para o consumo de drogas como problema de saúde apenas a partir da década de 1980, em resposta ao alto índice de transmissão do HIV entre consumidores de drogas injetáveis, conforme analisam Coelho et al. (2012), a partir de diversas fontes. Nesse momento, princípios da Redução de Danos (RD) foram acessados para embasar intervençóes que tomavam como objeto as doenças transmissíveis e como sujeitos os usuários de drogas das populaçóes marginalizadas e excluídas (SANTOS; SOARES; CAMPOS, 2007).

A partir da preocupação do estado com a transmissão do HIV, diversos conceitos e práticas de $\mathrm{RD}$ passaram a permear as políticas públicas e as produções acadêmicas. A moderna saúde pública começou a debater o consumo de drogas pelo ângulo do risco, conceito que leva em consideraçáo a instalação e evoluçáo de uma doença, a partir de um desequilíbrio na relação ambiente-hospedeiro-agente, gerando intervençôes sobre os fatores de risco que a epidemiologia relaciona com o problema (SOARES, 2007). A Saúde Coletiva critica essa vertente, por desagregar em fatores os determinantes sociais do processo saúde-doença, que são constitutivos das bases estruturais da sociedade, de forma que o contexto social é tomado apenas na condição de pano de fundo do problema (SOARES, 2007).

Os conceitos de RD como movimento social amplo, de reação à guerra às drogas e de droga como mercadoria, fundamentam as práticas de atenção a consumidores de drogas no referencial da Saúde Coletiva (SOARES, 2007). O objeto das práticas é o processo de produção, comércio e consumo das drogas e o sujeito, as classes sociais, constitui coletivo heterogêneo, submetido a condiçóes desiguais de reprodução social (SANTOS; SOARES; CAMPOS, 2007).

O referencial da Saúde Coletiva oferece bases para que se constituam no processo de produção em saúde práticas emancipatórias de RD (SOARES, 2007). Práticas emancipatórias de RD são as que articulam os problemas apresentados pelo consumo prejudicial de drogas com a totalidade social. São práticas solidárias e humanizadas que aproximam os sujeitos do processo de crítica à realidade. Nesse arcabouço, a educação constitui processo de fundamental importância para que se compreendam as bases das desigualdades sociais e da produção de açôes políticas direcionadas à transformação de condições mais globais (SANTOS; SOARES; CAMPOS, 2007).

Tal concepção tem sido denominada redução de danos emancipatória (RDE) e assume que as pessoas, usuárias ou não de drogas, fazem parte de grupos sociais, com diferentes possibilidades de reprodução social, submetidas que estão ao sistema de exploração capitalista. Nesse sistema, as drogas fazem parte do conjunto de mercadorias e o consumo de drogas se apresenta como resultante das contradiçóes sociais, atendendo a necessidades de alteraçáo da psicoatividade, de acordo com os valores predominantes na contemporaneidade. Reitera ainda a saúde como direito social e busca desenvolver práticas sociais e de saúde para além do controle das drogas ilícitas e da criminalização dos usuários, ou seja, práticas que incidam sobre os determinantes do consumo de drogas. Ademais, a RDE busca denunciar as desigualdades de reprodução social 
entre as diferentes classes e promover a compreensão das raízes dos problemas associados ao consumo prejudicial de drogas (SOARES, 2007).

A fim de operacionalizar a RDE, devem ser incorporadas as necessidades dos sujeitos a partir de seu cotidiano, sendo essencial compor projetos específicos e utilizar instrumentos apropriados a realidades específicas, já que discursos descolados da realidade produzem o afastamento dos sujeitos. Além disso, os projetos devem contar com a participação dos sujeitos, com a finalidade de defender seus direitos e convicçóes, enfrentando questôes como a criminalização das drogas, as desigualdades sociais, a política e o papel das instituiçóes sociais (SOARES; JACOBI, 2000).

Tomando como objeto deste estudo as práticas desenvolvidas em Centro de Atenção Psicossocial para Álcool e Drogas II (CAPS-AD) de uma cidade do estado de São Paulo, a partir da experiência de um processo de supervisão, objetiva-se discutir a supervisão como processo educativo emancipatório, com a finalidade de transformar as práticas da equipe de saúde, refletindo sobre o processo de produção em saúde e seu processo de trabalho.

\section{Procedimentos}

\section{teórico-metodológicos}

Em uma cidade do interior de Sáo Paulo de aproximadamente 80 mil habitantes, um CAPS-AD foi inaugurado, tendo como equipe técnica dois psicólogas, um terapeuta ocupacional, um assistente social/gerente, uma enfermeira, três auxiliares de enfermagem (que também desenvolviam funções administrativas), além de dois oficineiros (contratados para um ano de trabalho) ${ }^{1}$. Os profissionais técnicos eram concursados e não tinham experiência ou formação sobre a problemática de álcool e outras drogas, com exceçâo da gerente, que havia trabalhado em uma comunidade terapêutica e que desenvolvia açôes utilizando-se dos 12 passos $^{2}$ (alcoólicos anônimos e narcóticos anônimos).

Após oito meses da inauguração, a prefeitura da cidade providenciou uma supervisão por meio de contrato de seis meses, a fim de auxiliar a equipe em suas dificuldades técnicas. Os encontros ocorreram na própria unidade, com todos os profissionais presentes em horário de serviço, uma vez por mês, totalizando seis encontros.

Por supervisão entende-se um processo educativo que tem como objetivo integrar as atividades parcelares e refletir sobre o processo de trabalho, a fim de avaliar se o trabalho está respondendo às necessidades de saúde apresentadas pela populaçáa (TRAPÉ; SOARES; DALMASO, 2011). Nesse sentido, a finalidade da supervisão é superar as questóes colocadas pela dimensão técnica do trabalho sem negá-la, estabelecendo discussão de caráter político-técnico (SAVIANI, 2003), de forma que se domine o processo de trabalho em seus elementos (objeto, instrumentos, finalidade e produto), propiciando o desenvolvimento de responsabilidades de caráter social e político e a capacidade de contestar a realidade (FREIRE, 2000).

O processo educativo, nessa perspectiva, parte da realidade a ser transformada, constituída histórica e culturalmente, de forma que essa seja problematizada. Cabe ao supervisor mediar a relação dialógica estabelecida, isto é, uma relaçáo em que todos os envolvidos (supervisor e supervisionados) são sujeitos do processo e em que há mútuo aprendizado. Por ter uma síntese diferente daquela proveniente dos conhecimentos dos supervisionados, também cabe ao supervisor instrumentalizar a problematização em função das necessidades levantadas, para a compreensão das práticas sociais vigentes. A partir da mediação, espera-se que uma nova compreensão da realidade seja elaborada e expressa, isto é, que novas práticas sejam desenvolvidas (SAVIANI, 2003).

Coerentemente com o marco teórico adotado, notadamente de natureza crítica, buscou-se conhecer a realidade do serviço e do território em questão, bem como o processo de trabalho e a prática dos profissionais embasadas em conhecimento técnico-científico sobre o fenômeno das drogas e também em experiências profissionais prévias. Os profissionais elencaram as dificuldades encontradas no trabalho, que diziam respeito ao processo de trabalho fragmentado, à compreensão do processo saúde-doença pautado na multifatorialidade, ao conhecimento técnico limitado acerca do fenômeno das drogas e das políticas públicas voltadas a consumidores de drogas e aos recursos humanos e materiais disponíveis na unidade, que se mostravam insuficientes. Tal reconhecimento permitiu que fossem realizadas discussões a partir das experiências vivenciadas na unidade e de casos clínicos, de leitura de textos e sugestão de filmes.

\section{$3 \mathrm{O}$ processo da supervisão}

O processo da supervisão baseou-se no referencial teórico crítico da Saúde Coletiva, que compreende o processo saúde-doença como determinado socialmente, isto é, tem relação direta com as formas de trabalhar e de viver (LAURELL, 1982). 
O referencial crítico aponta que a partir da modernidade e com o advento da formaçáo social predominantemente capitalista, as drogas passaram a fazer parte do conjunto de mercadorias que respondem às necessidades de acumulação do capital (SOARES, 2007). As drogas, portanto, estáo inseridas de forma organizada no sistema de produção, distribuição e consumo da economia de mercado, representando a maior economia mundial, considerado o conjunto de drogas lícitas e ilícitas. Em relação apenas às drogas ilícitas, Arbex Junior (2012) afirma que são movimentados de $350 \mathrm{a}$ 500 milhôes de dólares ao ano, sendo que diariamente narcodólares são lavados em bancos e instituiçôes internacionais. Narcoprodutores e os narcotraficantes estão inseridos no mercado de trabalho, ainda que se esse se constitua paralelamente ao mercado oficial e ainda que tal inserção se deva em grande parte à falta de opçáo concreta de emprego no mercado formal.

Soares (2007) afirma que na base do consumo prejudicial de drogas estão sérias dificuldades de perspectivar o futuro, insegurança em relaçáo aos mecanismos de proteção social e necessidades de obtençáo de prazer imediato, condiçóes características da vida em sociedade, atualmente.

Diz-se, dessa forma, que as necessidades de saúde, que são necessidades sociais, extrapolam as possibilidades e atribuições funcionalistas do campo da saúde (CAMPOS; MISHIMA, 2005) de forma que promover saúde depende de transformar as práticas em saúde, articulando-as às de diversos setores, como trabalho, educação, saneamento básico e preservação ambiental, estando esses setores submetidos à política econômica (STOTZ; ARAUJO, 2004).

A experiência de supervisão fez reconhecer que o processo de trabalho nos CAPS-AD de fato exige dos trabalhadores que se comuniquem com outros setores: seja pelos princípios da Reabilitação Psicossocial ${ }^{3}$ (diretriz que está na base da formulaçáo dos serviços CAPS), seja pelas necessidades demandadas pelas pessoas atendidas: alimentação, abrigo, vestimenta, documentação, retomada de estudos, entre tantas outras. Essas práticas, entretanto, limitam-se aos encaminhamentos entre serviços, sendo as iniciativas de elaboração conjunta de açôes entre setores, difíceis e fragmentadas ${ }^{4}$ (COELHO, 2012).

Stotz e Araujo (2004) discute a necessidade de construir uma nova cultura para o setor saúde. Atualmente, a legitimidade das práticas em saúde baseia-se no saber técnico inquestionável por sua natureza científica. Uma suposta completude desse saber gera autoritarismo e centralização das práticas em saúde, limitando a elaboração criativa de outras respostas de saúde e de sujeitos náo certificados pela formação acadêmica (STOTZ; ARAUJO, 2004). Consequentemente, a prática em saúde integrada a outros setores também fica limitada. Dessa forma, compreendendo os problemas de saúde de forma mais ampla, a partir dos contextos de vida e da escassez de recursos, há de se reconhecer os próprios limites e validar, ao mesmo tempo, o saber do outro (STOTZ; ARAUJO, 2004).

Nesse sentido, estimulou-se durante o processo de supervisão o estabelecimento de comunicação e fortalecimento da rede social e de saúde, uma vez que essa prática não existia e os serviços funcionavam de forma não integrada. Uma ação proposta pela equipe foi o planejamento de um evento a fim de apresentar o CAPS-AD e o paradigma da RD aos demais equipamentos da saúde e assistência, planejando-se que o esclarecimento sobre o serviço seria o primeiro passo para a aproximação e o estabelecimento do funcionamento em rede.

A compreensão do objeto de trabalho pela equipe demandou discutir o paradigma que embasa as práticas que desenvolvem. Como já relatado por Campos e Soares (2003) em análise sobre a compreensáo do processo de trabalho de equipes de diferentes serviços de saúde mental, inicialmente a equipe demonstrou ter pouco acúmulo de discussão sobre o trabalho, de forma que a finalidade do trabalho do CAPS-AD estava obscurecida. Propunha-se nesse contexto, como finalidade para o trabalho, que os consumidores alcançassem a abstinência de drogas, por vezes acompanhada de desejos de boa convivência com sua família e, ainda, que os usuários se engajassem em alguma ocupaçáo. Tais finalidades propostas encontravam obstáculos na realidade, que eram explicados pelas dificuldades de mudança de comportamentos dos usuários de drogas.

Entre as culpabilizaçóes dos usuários e as da própria equipe, pelo não êxito em atingir tais finalidades, a equipe mostrou-se motivada a desenvolver práticas fundamentadas na $\mathrm{RD}$, sendo que para isso foram discutidos a política de atenção a usuários de drogas do Ministério da Saúde ${ }^{5}$, textos sobre a história da RD bem como a operacionalização desse paradigma no cotidiano da unidade.

Outra estratégia utilizada a fim de desenvolver novas práticas na unidade foi a discussão de casos atendidos pela equipe. Tal como a complexidade do fenômeno do consumo de drogas, os usuários do CAPS-AD também apresentam diversas necessidades de saúde que exigem uma resposta complexa. Observa-se atualmente, "[...] o aumento das necessidades, carências e demandas sociais e 
processos de precarização na prestação de serviços estatais [...]" (BEZERRA, 2011, p. 243). Como resposta a essa realidade, os serviços têm assumido caráter emergencial, direcionado aos que não têm poder de compra, dada sua reprodução social (BEZERRA, 2011).

Os profissionais da unidade sentiram necessidade de discutir casos de difícil encaminhamento. Independentemente da especificidade do caso, questôes sociais como não ter onde morar, ter família pouco disposta a lidar com o consumidor de drogas, ter dificuldade em empregar-se no mercado de trabalho formal, que garante os direitos enquanto cidadáo, não ter o reconhecimento das outras pessoas, não ter acesso a lazer, uma vez que o estado não se faz presente no território onde vivem, entre outras, permearam as discussóes.

Percebeu-se que, por mais que ações técnicas de enfrentamento ao consumo problemático de drogas fossem desenvolvidas, a equipe de saúde não tinha instrumentos para lidar com as questóes sociais que se apresentavam. Ademais, a fragmentação existente no processo de trabalho, que culmina na perda da noção de conjunto do processo pelo trabalhador, minava o envolvimento afetivo e intelectual dos trabalhadores com o seu fazer.

Nesses casos mais difíceis, a compreensão do processo saúde-doença como socialmente determinado, do paradigma da redução de danos emancipatória e da intersetorialidade, a partir da constituição de rede social e de saúde, foi essencial para nortear as práticas do serviço. Além disso, contribuíram para que os profissionais desculpabilizassem os usuários do serviço pelo "fracasso" do tratamento e também para que se sentissem menos frustrados com o trabalho desenvolvido, que apresentava resultados pouco animadores.

A compreensão de que a mudança de comportamento não depende da força de vontade individual e de que a insistência nesse objetivo traria apenas mais frustraçóes para os usuários de drogas e para os profissionais trouxe a reflexão sobre a necessidade de os profissionais adotarem, para além da dimensão biológica e psicológica, práticas de caráter político, discutindo os determinantes do processo saúde-doença e as diferentes realidades das classes sociais. Além disso, ficou claro que formas de enfrentamento das desigualdades também deveriam ser discutidas com os usuários do serviço, a fim de que pudessem contestar a realidade e se instrumentalizar para transformá-la.

\section{Discussão}

Os profissionais de saúde recebem formação pautada no paradigma dominante da moderna saúde pública, que compreende o processo saúde-doença a partir de fatores fragmentados, capazes de isolar o sujeito de sua condição social, e que produz práticas condizentes com o status quo (SOARES, 2007). No caso específico do consumo de drogas, a formação recebida se mostra insuficiente ou inadequada para lidar com tamanha complexidade (COELHO, 2012), haja visto que o contato com o tema na graduação, na área da saúde em geral acontece através das disciplinas de psiquiatria e/ou farmacologia, isto é, estudam-se apenas alguns recortes do fenômeno, os de natureza biomédica (SOARES, 2007).

Esse contexto se agrava na medida em que não há espaços de discussão acerca das necessidades de saúde dos grupos sociais e do processo de produção em saúde - seja na formação, seja no processo de trabalho -, acarretando práticas simplistas no campo de atenção a consumidores de drogas, que pouco contribuem para a saúde das pessoas atendidas e que não se direcionam a compreender os determinantes sociais do processo saúde-doença ou a confrontá-los (COELHO, 2012).

A manutenção das práticas pautadas na moderna saúde pública, que responsabiliza o sujeito por sua saúde e por seu adoecimento, visando tratar os problemas de saúde já instalados, não dão conta das necessidades de saúde demandadas pelos grupos sociais (SOARES; SALUM, 1999). No que tange ao consumo prejudicial de drogas, essa lógica se aproxima do paradigma de guerra às drogas, que propóe a mudança de comportamento dos consumidores de drogas sem alterar as condiçóes que estão na sua raiz. Esse paradigma encontra na droga um inimigo a ser combatido de forma policialesca, negando a historicidade e a cultura do uso de drogas que acompanha a humanidade (CARNEIRO, 2002).

A produção em saúde pautada nessa perspectiva produz frustraçóes tanto para o usuário do serviço, que se sente fracassado e incapaz, quanto para o profissional, que sofre processo de desgaste pelo trabalho, devido a poucos resultados efetivos. Ribeiro, Pires e Blank (2004) apontam que os trabalhadores que encontram dificuldades no trabalho acabam sentindo-se inseguros, desconfiados de sua capacidade e amedrontados. Ainda, nos dias de hoje há prevalência de mal-estares difusos entre os trabalhadores, tais como fadigas, dores de cabeça e nas costas, dificuldades para dormir, além de obesidade e sintomas subjetivos, que não costumam ser associados às atividades laborais (COSTA; 
TAMBELLINI, 2009; ABRAMIDES; CABRAL, 2003; LACAZ, 2000).

Esses sintomas difusos têm raízes nas formas de trabalhar, na fragmentaçáo do processo de trabalho. Conforme analisam Trapé, Soares e Dalmaso (2011), apoiadas em Marx, assim como nos demais campos, os processos de produção em saúde comportam distintos processos de trabalho e estão submetidos à divisão do trabalho, que separa o trabalhador do produto de seu trabalho. Como consequência, tem-se a perda de controle sobre o processo de trabalho, isto é, a compreensão do conjunto do processo de trabalho - objeto, instrumentos, finalidade, produto - fica prejudicada.

O papel da supervisão, então, é o de estimular os profissionais à condição de sujeitos do processo de trabalho do qual participam a partir da reflexão sobre os elementos desse processo, para apropriar-se culturalmente de seu produto. No caso do processo aqui investigado, o produto do processo de trabalho se configura como a satisfação das necessidades de saúde dos usuários do serviço, por isso trata-se do desenvolvimento de práticas coletivas de âmbito político, para além do cuidado individual.

Superando a matriz clínico-biológica hegemônica, apreendida na formação em saúde, a reduçáo de danos emancipatória consubstancializa a historicidade, a reproduçáo social, a classe e a individualidade do sujeito, apresentando-se, dessa forma, como movimento político para fundamentar as práticas desenvolvidas pelos profissionais do CAPS-AD.

\section{Considerações finais}

O esforço da supervisão descrita concentrou-se na finalidade de apoiar os profissionais de saúde no domínio dos elementos do processo de trabalho, a fim de que o objeto das práticas no serviço fosse revisto. O processo também teve como finalidade apresentar a redução de danos emancipatória e discutir o significado de sua adoção para nortear as práticas. No sentido de compreender como o processo de produção de práticas em saúde é reproduzido socialmente, foi também discutida a dimensão política.

Apesar de o processo ter como horizonte a desmistificaçáo tanto da droga, adotando a compreensão da droga como mercadoria, como da determinação social do processo saúde-doença, dificuldades foram encontradas no desenvolvimento de práticas que tivessem a redução de danos emancipatória como fundamento.

As dificuldades encontradas podem ser atribuídas à quantidade insuficiente de tempo para o processo educativo de supervisão, à falta de espaços de discussão instituídos no cotidiano da unidade, o que traz obstáculos concretos à análise dos profissionais sobre os processos de trabalho de que participam, além da mudança de governo ao longo do processo, que instaurou relação hierárquica sem possibilidade de contestação e exigiu dos profissionais o desenvolvimento de prática baseada nos cânones da guerra às drogas, causando retrocesso no processo de construção de práticas emancipatórias da equipe da unidade.

No entanto, levando em consideraçáo o aumento das demandas sociais postas aos trabalhadores devido à precária presença do estado nos territórios, o que exige dos profissionais novas competências e habilidades (BEZERRA, 2011), a supervisão possibilitou a ampliação dos conhecimentos técnicos e políticos da equipe sobre o fenômeno do consumo de drogas. A equipe passou a adotar a perspectiva de que o setor saúde deve integrar a rede intersetorial de recursos e serviços como mais um passo no sentido de dar conta da complexidade de intervir em saúde nessa área. Além disso, a equipe de saúde passou a discutir o processo de trabalho de que participa, em especial o objeto de trabalho, minimizando a fragmentação decorrente da divisão técnica do trabalho.

A supervisão configurou-se como processo educativo crítico, visando à emancipação dos usuários do serviço, a partir do desenvolvimento de práticas da equipe de saúde fundamentadas na redução de danos emancipatória.

\section{Referências}

ABRAMIDES, M. B.; CABRAL, M. S. R. Regime de acumulação flexível e saúde do trabalhador. São Paulo em Perspectiva, São Paulo, v. 17, n. 1, p. 3-10, 2003.

ARBEX JUNIOR, J. Economia do mercado das drogas. In: SEMINÁRIO A CRACOLÂNDIA MUITO ALÊM DO CRACK, 2012, São Paulo. São Paulo: FSP-USP, 2012.

BEZERRA, W. C. O Estado brasileiro e o ataque neoliberal: algumas reflexôes para a terapia ocupacional. Cadernos de Terapia Ocupacional, São Carlos, v. 19, n. 2, p. 239-248, 2011.

BONIS, G. Ação da polícia parte de visão higienista. Carta Capital, São Paulo, 2012. Disponível em: < http:// www.cartacapital.com.br/sociedade/acao-da-policiaparte-de-visao-higienista>. Acesso em: 24 agosto 2013. BRASIL. Ministério da Saúde. Secretaria de Atenção à Saúde. Coordenação Nacional de DST e AIDS. A política do Ministério da Saúde para atenção integral a usuários de álcool e outras drogas. Brasília, 2004.

BUCHER, R. Drogas e drogadição no Brasil. Porto Alegre: Artes Médicas, 1992.

CAMPOS, C. M. S.; MISHIMA, S. M. Necessidades de saúde pela voz da sociedade civil e do Estado. 
Caderno de Saúde Pública, Rio de Janeiro, v. 21, n. 4, p. 1260-1268, 2005.

CAMPOS, C. M. S.; SOARES, C. B. A produção de serviço de saúde mental: a concepção dos trabalhadores. Ciências \& Saúde Coletiva, Rio de Janeiro, v. 8, n. 2, p. 621-628, 2003.

CARNEIRO, H. S. As necessidades humanas e o proibicionismo das drogas no século XX. Instituto de Estudos Socialistas, São Paulo, n. 6, p. 115-128, 2002.

COSTA, D. O.; TAMBELLINI, A. T. A visibilidade dos escondidos. Physis: Revista de Saúde Coletiva, Rio de Janeiro, v. 19, n. 4, p. 953-68, 2009.

COELHO, H. V. A atenção ao usuário de drogas na Atençáo Básica: elementos do processo de trabalho em Unidade Básica de Saúde. 2012. 224 f. Dissertação (Mestrado)-Escola de Enfermagem da Universidade de São Paulo, São Paulo, 2012.

COELHO, H. V. et al. Políticas públicas de saúde aos usuários de álcool e outras drogas: contribuição da Saúde Coletiva ao debate. Revista de Ciências da Saúde da Faculdade Estácio de Sá de Goiás, Goiânia, v. 2, n. 7, p. 194-203, 2012.

FREIRE, P. Educação como prática da liberdade. São Paulo: Paz e Terra, 2000.

LACAZ, F. A. C. Qualidade de vida no trabalho e saúde/ doença. Ciência \& Saúde Coletiva, Rio de Janeiro, v. 5, n. 1, p. 151-161, 2000.

LAURELL, A. C. La salud-enfermedad como processo social. Revista Latinoamericana de Salud, Mexico, v. 1, n. 2, p. 7-25, 1982

NAPPO, S. Epidemia! Existe para o crack? In: SIMPÓSIO CRACK, 2., 2012, São Paulo. São Paulo: UNIFESP; CEBRID, 2012.

RIBEIRO, E. M.; PIRES, D.; BLANK, V. L. G. A teorização sobre processo de trabalho em saúde como instrumental para análise do trabalho no Programa de Saúde da Família. Caderno de Saúde Pública, Rio de Janeiro, v. 20, n. 2, p. 438-46, 2004

SANTOS, V. C.; SOARES, C. B.; CAMPOS, C. M. $S$. A relação trabalho-saúde de enfermeiros do PSF no município de São Paulo. Revista da Escola de Enfermagem USP, São Paulo, v. 41, p. 777-781, 2007. Número especial.

SARACENO, B. A reabilitação como cidadania. In: SARACENO, B. Libertando identidades: da reabilitação psicossocial à cidadania possível. Rio de Janeiro: TeCorá, 1999. p. 111-142. (cap. 5).

SAVIANI, D. Pedagogia histórico-crítica. Campinas: Autores Associados, 2003.

SOARES, C. B. Consumo contemporâneo de drogas e juventude: a construção do objeto na perspectiva da Saúde Coletiva. 2007. 195 f. Tese (Livre-docência)-Escola de Enfermagem da Universidade de São Paulo, São Paulo, 2007.

SOARES, C. B.; SALUM, M. J. L. A instrumentalização da inteligência popular e a intervençâo em saúde coletiva. São Paulo: Escola de Enfermagem da USP; Departamento de Enfermagem em Saúde Coletiva, 1999. (Documento de apoio pedagógico).

STOTZ, N. E.; ARAUJO, J. W. G. Promoção de saúde e cultura política: a reconstrução do consenso. Saúde e Sociedade, São Paulo, v. 13, n. 2, p. 5-19, 2004.

TRAPÉ, C. A.; SOARES, C. B.; DALMASO, A. S. W. Trabalho do agente comunitário de saúde: a dimensão educativa da supervisão. Sociedade em Debate, Pelotas, v. 17, n. 1, p. 117-138, 2011.

VENDRAME, A.; PINSKY, I. Ineficácia da autorregulamentação das propagandas de bebidas alcoólicas: uma revisão sistemática da literatura internacional. Revista Brasileira de Psiquiatria, Rio de Janeiro, v. 33, n. 2, p. 2011-2017, 2010.

\section{Contruibuição dos Autores}

Luciana Cordeiro: Concepção do texto, redação e revisão. Aline Godoy e Cassia Baldini Soares: Redação e revisão do texto.

\section{Notas}

${ }^{1}$ Agradecemos a equipe que participou da supervisão e concordou com a publicação da experiência.

${ }^{2}$ Os 12 passos são uma metodologia voltada a dependentes químicos que se autodenominam "irmandade de homens e mulheres que compartilham suas experiências, forças e esperanças, a fim de resolver seu problema comum e ajudar outros a se recuperarem do alcoolismo. O único requisito para se tornar membro é o desejo de parar de beber" (http://www. alcoolicosanonimos.org.br).

${ }^{3}$ Reabilitação Psicossocial - Uma noção de Reabilitação que tem como sentido a construção dos direitos substanciais: afetivos, relacionais, materiais, habitacionais, produtivos e culturais dos sujeitos (SARACENO, 1999).

${ }^{4}$ Embora não seja nosso intuito focar no debate sobre a privatização dos setores saúde e assistência social, é relevante mencionar que ela interfere diretamente no processo da intersetorialidade, a qual, orientada pela lógica empresarial, limita os processos de trabalho ao cumprimento de metas, competitividade, e limita também a solidariedade e o compartilhamento de informaçōes e conhecimentos.

${ }^{5} \mathrm{O}$ Brasil conta com duas políticas públicas voltadas a usuários de drogas, quais sejam: a política do Ministério da Saúde, pautada no paradigma da redução de danos, e a política da Secretaria Nacional sobre Drogas (SENAD), do Ministério da Justiça, notadamente pautada nos cânones da guerra às drogas (COELHO, 2012; COELHO et al., 2012). 